\title{
Analysis on Project Performance Management of Calling Center
}

\author{
Qiaoman Liu \\ Jiangsu Vocational Institute of Commerce, Nanjing Jiangsu, 211168, China
}

Keywords: Calling center, Project performance management, Design, Identification.

\begin{abstract}
As economic development level improves continually, calling center gains rapid development and progress. As technology becomes mature and the industry improves continuously, calling center operates more smoothly. Performance management is a very important content and also the emphasis of performance management. But, there is certain gap between actual competition effect and expected performance objective, and it is very hard to pre-control the implementation process. This paper will analyze design optimization, identification method and performance control of calling center and proposes several effective suggestions on how to carry out performance management under the guidance of project management theory, in the hope of offering reference for performance management of calling center.
\end{abstract}

\section{Introduction}

Under rapid development of market economy, competitions among enterprises become increasingly fierce. Severe product homogenization problem occurs, and replicability also intensifies. In such trend, enterprises expand market one after another in order to gain competitive edge, keep product optimization and innovation and improve service quality. Besides, customer satisfaction and customer loyalty can improve through increasing the added value of products so as to achieve sustainable and optimal development of products. An important means to communicate between enterprises and customers is calling center. So, calling center is used by many enterprises. Calling center develops fast in China. As data size increases, efficient management is required in order to better achieve scientific and digital operation calling. Thus, efficient management should serve as the key point of the research on calling center.

\section{Overview of calling center project operation}

Calling center operating enterprises need the support of more professional personnel. Hence, it is necessary to continuously recruit and train professional talents with rich knowledge and strong operation management ability. Moreover, the performance and function of calling center should be enhanced. The features are as follows:

High cost and low profit. Communication fee is main cost of calling. In view of heavy workload, dull work and single form of calling center, the recruitment difficulty of calling center further increases. Calling center has very low industrial threshold, and small calling centers spring up continuously. Thus, competitions become disorderly, and the price war lasts. It is very difficult to improve operation profit. Short operation time and heavy task. The implementation time of outsourcing projects of calling center is usually short. To reach a specific economic goal, many means will be taken. But due to the limits of personnel, site and resources, the projects will be outsourced to other calling center enterprises and enterprises are required to complete all work within the specified time. Diversified demands and significant individuation. Calling center faces all kinds of customers, and every customer has different demands. Individuation requirement is thus generated. Thus, it is required to choose suitable management personnel for training before the project is launched, optimize and adjust calling center business system and arrange work well. Thus, the first resource of calling center is "human", while the core is high-quality management mode. Only when the two cooperate with each other can calling center operate more stably and efficiently ${ }^{[1]}$. 


\section{Method to implement project performance management of calling center}

\section{Construct efficient calling center performance management system.}

To improve the efficiency of calling center performance management, firstly, planned performance management system should be constructed, and brought into resource management. Meanwhile, the objective should be decomposed and assigned to the specific persons in order to improve enterprise performance level.

It is required to detail position duties and formulate performance assessment norms. Before performance management index system is constructed, different position duties should be specified, and each duty should be detailed so that every worker of calling center is familiar with the content of Position Duty Specification, different work procedures, reward and punishment indexes and promotion indexes, and know quality and skills.

It is required to decompose, detail and establish performance index system. Besides, it is required to decompose and quantify the entire objective in strict accordance with the content of Position Duty Specification, implement each job objective in the specific position and make quantitative performance index system more complete. In addition, work procedure ad measures can be formulated through negotiating with the superior organization so that the plan can be strictly made and implemented. A key index of calling center evaluation is customer satisfaction. Performance indexes can be decomposed and detailed. As well, "call completing rate, service quality and employee efficiency" indexes should be formed at the management level. At the level of telephone operators, a series of quantitative indexes should be formed to enhance call completing rate and service quality, including online utilization ratio and first solution rate, service level and so on ${ }^{[2]}$. The indexes of grass-roots personnel are shown in Table 1.

Table 1 Performance indexes of grass-roots personnel in calling center

\begin{tabular}{llll}
\hline Name of index & & & Index value \\
\hline System platform & 1 & Busy tone rate & $2 \% \sim 5 \%$ \\
\cline { 2 - 4 } & 2 & Call dropping probability & $<3 \%$ \\
\cline { 2 - 4 } & 3 & Busy rate & $65 \%$ \\
\cline { 2 - 4 } & 4 & Abandonment rate & $4 \% \sim 6 \%$ \\
\hline Seat management & 1 & Turnover rate of grass-roots personnel & $12 \% \sim 50 \%$ \\
\cline { 2 - 4 } & 2 & Attendance rate & $86 \%$ \\
\cline { 2 - 4 } & 3 & Practical work rate & $90 \%$ \\
\cline { 2 - 4 } & 4 & Seat utilization rate & $60 \% \sim 80 \%$ \\
\hline
\end{tabular}

It is required to check step by step and implement performance closed-loop management. As the core of project management, closed-loop management is also the key point. To make sure project implementation is pre-controlled, project management should be enhanced. Calling center management is also the emphasis of process supervision, and basic principles of closed-loop management should be followed in performance management. In this way, performance management can be conducted continuously, and performance management is more effective. As the center link of project operation, performance management should pass through the project, form closed-loop management should be formed in performance management.

\section{Form PDCAC performance closed-loop process management.}

A very important management idea in project management is closed-loop management. Meanwhile, process control should be done well. Besides, it is required to follow closed-loop requirement in calling center performance management, abide by PDCAC cycle concept and make sure performance management cam gain sustainable management and optimization. The application of closed-loop management cycle theory is the key to making sure performance indexes are completed orderly and smoothly.

1) $P$ (PLAN) - performance index system plan

It is necessary to start from overall strategy of center, combine customer perception, establish hierarchical performance index system concept and specify main tasks and work core of each position. In this way, key performance indexes can be confirmed, and performance index system can be formulated rationally. 


\section{2) $D(D O)$ - implement performance indexes}

After the performance indexes are formulated, it is required to detail work measures, make work plan, form annual work plan and achieve full utilization of resources in strict accordance with the guidance of annual plan, implement position standards in the limited time and achieve performance objective. Managers should lead the subordinate employees to achieve organizational performance. Customer service representatives urge personnel to continuously optimize their work ability under new performance indexes and better fulfill the work requirements.

3) C (CHECK) - performance process monitoring

During optimal management of the same project process, project work should be monitored to make sure the project is completed efficiently. In performance management, the implementation of different performance indexes should be detected and monitored. Product service based on calling center should reflect timeliness and irreversibility. Besides, calling center performance management should be enhanced. In particular, service performance evaluation of customer service representatives should reflect timely control. It is necessary to gather and analyze data in services, explain various work indexes with data, reduce service deviation as far as possible and make the overall level of calling center improve.

4) A (ACTION) - performance improvement

Performance monitoring is also an important index which measures job performance competition of center managers and customer service representatives. On this basis, it is required to continuously improve performance and follow the basic principle of "correcting mistakes, if any" . For the customer service representatives who perform well, they should be encouraged and rewarded properly so as to improve their work enthusiasm. For the customer service representatives who perform poorly, they should be encouraged too, and feasible improvement measures should be formulated. For organizational performance, god norms can be kept, but bad norms should be improved. Under continuous cycle of PDCA, performance indexes for all personnel can be formulated and completed . meanwhile, the whole service level of calling center can improve ${ }^{[3]}$.

5) C (COMMUNICATION) - performance communication

Making sure performance executors understand performance and have full understanding of performance execution deviation is an important guarantee for effective implementation of indexes. As well, communication should be enhanced in performance management, which is also a key point. performance management can be implemented in an orderly and healthy way only through timely and rational communication. In different stages of performance management, performance communication also has different emphases. In the planning stage, performance understanding concerns whether the opinion can reach an agreement, while the execution emphasis lies in management, guidance and help. In the monitoring stage, deviation analysis is also a key job. In the communication stage, it is necessary to communicate and negotiate with relevant personnel so as to better execute and implement work ${ }^{[4]}$.

In PDCAC performance management mode, closed-loop performance management should be used. In performance management, data should be communicated, improved and evaluated continuously, and fine management principle of calling center should be enhanced continuously. In this way, dynamic performance control can be achieved.

\section{Establish timely and effective performance communication mechanism.}

PDCAC performance management mode mentioned above has many advantages and occupies an important position in the whole communication link. Similarly, communication management is a very important content in project management. The performance objective can be pre-controlled and performance objective can be achieved only when effective performance communication is executed. But, the past calling center performance management ignored this problem. Annual evaluation is conducted from top management to grass-roots personnel, and the leader needs to complete more work, but communication decreases step by step. Thus, it is necessary to establish both-way contact in efficient calling center performance management, discover deviation and correct deviation in time, retrospect communication mode regularly, find problems in communication in time, enhance 
discussion and correction of problems and carry out communication from performance process monitoring, performance formulation and evaluation. The following aspects can be considered:

1) Formulate performance and adopt hierarchical and both-way communication method

In order to make performance get support and approval of personnel at each level, hierarchical and both-way communication should be implemented. During performance formulation, both-way communication plays a great role. In view of intensive personnel of calling center, performance formulation and communication uses both-way communication to implement superior index system and performance communication step by step. Then, hierarchical decomposition and implementation mode forms. In this way, all personnel can understand performance objective, devote themselves to achieving performance objective, enhance work enthusiasm and improve the whole atmosphere.

2) on-site monitoring and real-time communication

It is suggested that customer representatives of calling center use "side-by-side" monitoring method and appky real-time communication mode in performance communication. Performance management system is introduced, and system daily report is used every day to evaluate and monitor the work of customer service representatives. As well, the problems should be found in time. Both-way performance communication is conducted between evaluators and those to be evaluated. Regular training and guidance are needed to strengthen dynamic management of personnel and reduce the probability of deviation. These have important significance for achieving organizational and individual objective.

3) Organizational performance, monthly follow-up and timely communication

Enhancement of project time management is also the emphasis of organizational performance monitoring. It can reduce the situations of poor work and avoid performance management time error. The calling center can follow performance indexes monthly and form "monthly monitoring" mechanism. Through following up performance objective, the problems can be found in time, and rational performance index optimization method can be formulated.

4) Build performance team, implement quarterly inspection and enhance communication

After performance management team is built, performance completion condition should be inspected and evaluated quarterly to specify the competition conditions of different departments. Through both-way communication, the difficulties of different departments can be known in time, and corresponding guidance should be provided. It is required to discover problems in production, urge relevant departments to correct the deviation in time and then make sure performance work is completed more smoothly ${ }^{[5]}$. Through multi-level and high-frequency communication and guidance, work objective conversion can be enhanced, and linear multi-level management can be finally achieved. As well, the risk of objective deviation can be smoothly evaded. Performance management communication runs through performance management, because performance management is a long-term and complex process. The performance objective involved can offer reference. Performance setting, implementation and evaluation should serve as an integral whole, and each link should be implemented and enhanced so as to discover and solve problems and make sure performance objective is archived smoothly.

\section{Conclusion}

In general, project performance management of calling center is a complex and long-term process. In order to achieve project performance management, overall control calling center performance and improve operation performance of calling center, it is required to improve service level, let customer satisfy services and enhance market competitiveness. This paper analyzes the application of project performance management of calling center and shows that an important precondition of enhancing core competitiveness of calling center is performance management optimization.

\section{Acknowledgments}

This paper is a key topic of the university, No.: JSJM1408. 


\section{References}

[1] Zhu Yijun, Zhang Jiguo, Wang Wei et al., Analysis of calling center property based on changeable service rate $\mathrm{M} / \mathrm{M} / \mathrm{S} / \mathrm{K}+\mathrm{M}$ repairable queuing, Journal of Jiangsu University (Natural Science), 2010,27(4):368-371.

[2] Yu Miao, Gong Jun, Tang Jiafu et al., Human resource allocation method of calling center with queuing information prompt, Journal of Northeastern University (Natural Science), 2014,35(1):1-4,14.

[3] Yang Xueliang, Li Junxiang, Tai Yuhong et al., Manpower demand calculation method of calling center based on ant colony algorithm, Application Research of Computers, 2015,32(7):1962-1965,2038.

[4] Xu Hui, Tang Xingchun, Li Jingmin et al., Verification of incentive mechanism effectiveness of tax information operation and maintenance service calling center, Enterprise Science And Technology \& Development, 2014(23):3-5.

[5] Gan Wenli, Zhang Kunpeng, Feng Chunming et al., Application of jBPM in customer service quality management system of calling center, Journal of Inner Mongolia Normal University (Natural Science Chinese), 2013(3):344-349. 